\title{
Asthma control and quality of life in patients with moderate or severe asthma*
}

\author{
Controle da asma e qualidade de vida em pacientes com asma moderada ou grave* \\ Eanes Delgado Barros Pereira, Antonio George de Matos Cavalcante, \\ Eduardo Nolla Silva Pereira, Pedro Lucas, Marcelo Alcântara Holanda
}

\begin{abstract}
Objective: To evaluate the association between degree of asthma control and health-related quality of life in patients with moderate or severe asthma. Methods: This was a descriptive observational study involving 59 outpatients with moderate or severe asthma under treatment at the Asthma Outpatient Clinic of the Federal University of Ceará Walter Cantídio University Hospital, in the city of Fortaleza, Brazil. The patients were evaluated regarding sociodemographic and clinical characteristics, as well as spirometric parameters. The asthma control status was assessed using the asthma control test (ACT), and quality of life was assessed using the Saint George's Respiratory Questionnaire (SGRQ). Results: The mean age of the patients was $55.0 \pm 12.4$ years, and 76.3\% were female. The ACT score showed statistically significant negative correlations with all SGRQ scores: total $(r=-0.72)$; symptoms $(r=-0.78)$; activity $(r=-0.67)$; and impact $(r=-0.68)$. Multiple regression analysis showed that the most robust predictive variables for SGRQ total score were ACT score (coefficient $=-3.18 ; 95 \% \mathrm{Cl}:-4.14$ to -2.23 ) and duration of disease (coefficient $=-0.29 ; 95 \% \mathrm{Cl}:-0.54$ to -0.03 ). The ACT score also explained the linear variation of the SGRQ domains: symptoms (coefficient $=-3.41 ; 95 \% \mathrm{Cl}$ : -4.45 to -2.37 ); activity (coefficient $=$ $-3.07 ; 95 \% \mathrm{Cl}$ : -4.57 to -1.57 ); and impact (coefficient $=-2.68 ; 95 \% \mathrm{Cl}:-3.71$ to -1.65 ). Conclusions: The degree of asthma control appears to have a significant impact on health-related quality of life.
\end{abstract}

Keywords: Asthma/prevention and control; Quality of life; Questionnaires.

\section{Resumo}

Objetivo: Avaliar a associação entre o estado de controle da asma e a qualidade de vida relacionada à saúde em pacientes com asma moderada ou grave. Métodos: Estudo descritivo observacional com 59 pacientes portadores de asma moderada ou grave, acompanhados no Ambulatório de Asma do Hospital Universitário Walter Cantídio da Universidade Federal do Ceará, em Fortaleza (CE). Os pacientes foram avaliados quanto a dados sociodemográficos, clínicos e espirométricos. 0 estado de controle da asma foi avaliado através do asthma control test (ACT) e a qualidade de vida através do Saint George's Respiratory Questionnaire (SGRQ). Resultados: A média de idade dos pacientes foi de 55,0 \pm 12,4 anos, e 76,3\% eram do sexo feminino. Foram observadas correlações negativas significantes entre os escores do ACT e todos os escores do SGRQ: total $(r=-0,72)$; sintomas $(r=-0,78)$; atividade $(\mathrm{r}=-0,67)$; e impactos $(\mathrm{r}=-0,68)$. A análise de regressão múltipla mostrou que o escore do SGRQ total teve como variáveis preditivas mais robustas o escore do ACT (coeficiente $=-3,18$; 1C95\%: $-4,14$ a -2,23) e tempo de doença (coeficiente $=-0,29$; 1C95\%: $-0,54$ a -0,03). 0 escore do ACT também explicou linearmente a variação do SGRQ em seus domínios: sintomas (coeficiente $=-3,41$ e 1C95\%: -4,45 a -2,37); atividade (coeficiente $=-3,07$ e 1C95\%: $-4,57$ a -1,57); e impactos (coeficiente $=-2,68$ e 1C95\%: $-3,71$ a $-1,65$ ). Conclusões: Na amostra estudada, 0 estado de controle da asma parece ser fortemente associado à melhor qualidade de vida relacionada à saúde.

Descritores: Asma/prevenção e controle; Qualidade de vida; Questionários.

\footnotetext{
* Study carried out in the Department of Clinical Medicine, Federal University of Fortaleza, Fortaleza, Brazil. Correspondence to: Eanes Delgado Barros Pereira. Rua Bárbara de Alencar, 1401, CEP 60140-000, Fortaleza, CE, Brasil. Tel. 5585 494-9000. E-mail: eanes@fortalnet.com.br

Financial support: Eduardo Nolla Silva Pereira and Pedro Lucas are recipients of scholarships from the Fundação Cearense de Apoio à Pesquisa (FUNCAP, Foundation for the Support of Research in the state of Ceará).

Submitted: 9 June 2011. Accepted, after review: 11 August 2011.
} 


\section{Introduction}

Bronchial asthma is a chronic inflammatory syndrome that is highly prevalent worldwide, affecting approximately 300 million individuals of all ages. ${ }^{(1)}$

The concept of asthma control includes clinical and functional manifestations, such as symptoms, nocturnal awakenings, use of rescue medication, activity limitation, and pulmonary function. The risk of future diseaseand treatment-related complications, including exacerbations, accelerated decline in pulmonary function, and adverse effects of drugs, should also be considered.(2) Asthma education and careful pharmacological management are essential interventions for disease control. Uncontrolled asthma can result in limitations of activities of daily living and even death. ${ }^{(2,3)}$

The asthma control test (ACT) questionnaire was developed with the objective of estimating the degree of asthma control. This tool provides information on the multidimensional nature of the disease. ${ }^{(4)}$ A Brazilian Portuguese-language version of the ACT has recently been validated. ${ }^{(5)}$

In recent years, various generic and specific instruments have been developed to estimate, in a multidimensional way, the impact that diseases have on health-related quality of life. The Saint George's Respiratory Questionnaire (SGRQ), developed by Jones et al., ${ }^{(6)}$ is a specific questionnaire for assessing quality of life in patients with chronic respiratory diseases. It has been translated, cross-culturally adapted, and validated for use in several countries, including Brazil. ${ }^{(7)}$

Asthma can result in physical, emotional, and social limitations for patients. These limitations can impair patient quality of life. In general, the quality-of-life impairment in asthma patients is proportional to the degree of disease activity. (8-12) Rational asthma management leads to disease control and better quality of life. Studies using specific questionnaires for assessing the association between asthma control and quality of life are scarce and controversial. ${ }^{(13,14)}$

In view of these considerations, the objective of the present study was to assess the association between health-related quality of life and degree of asthma control, as determined by the ACT, in outpatients with moderate to severe asthma under regular treatment at the Asthma Outpatient Clinic of the Hospital Universitário
Walter Cantidio da Universidade Federal do Ceará (HUWC-UFC, Federal University of Ceará Walter Cantídio University Hospital), located in the city of Fortaleza, Brazil.

\section{Methods}

This was an observational study conducted at the Asthma Outpatient Clinic of the HUWC-UFC. The study was predominantly descriptive. The study protocol was approved by the local research ethics committee, and all patients gave written informed consent.

We consecutively selected patients who had been diagnosed with moderate or severe asthma, in accordance with the Global Initiative for Asthma criteria, ${ }^{(2)}$ were over 18 years of age, and had been under outpatient treatment for more than six months. The patients were enrolled between September of 2009 and April of 2010. All patients were using an inhaled corticosteroid in combination with an inhaled long-acting $\beta_{2}$ agonist.

Sociodemographic data (age, gender, and level of education), as well as data regarding duration of disease and presence of comorbidities (diabetes, systemic arterial hypertension, allergic rhinitis, and gastroesophageal reflux [GER]), were collected through a questionnaire. Patients were assessed for rhinitis and GER on the basis of clinical criteria. Cases of allergic rhinitis were defined as those in which patients had recurrent episodes of wheezing, rhinorrhea, pruritus, and nasal congestion that were triggered by respiratory irritants, and cases of GER were defined as those in which patients had had more than two episodes of heartburn per week for more than four weeks.

We used spirometric data, such as FEV ${ }_{1}$, which was measured before and after administration of a short-acting inhaled $\beta_{2}$ agonist. Spirometry was performed in accordance with the Brazilian Thoracic Association guidelines. ${ }^{(15)}$ To assess asthma control, we used the ACT, and to assess quality of life, we used the SGRQ.

The ACT was developed to assess asthma control, and it has shown strong evaluative and discriminative properties. $^{(4)}$ It consists of five questions, related to the four weeks preceding the evaluation, addressing multiple dimensions of control, including episodes of breathlessness, nocturnal awakenings, limitations in activities of daily living, self-rating of asthma control, 
and need for rescue medication. The total score ranges from 5 to 25 points. A score $\geq 20$ on the ACT is indicative of controlled asthma.

The SGRQ addresses aspects regarding three domains: symptoms; activity; and psychosocial impact of the disease. Each domain has a maximum possible score. The scores obtained for all of the questions in a given domain are summed, and the total is expressed as a percentage of the maximum for that domain. Higher scores correspond to poorer quality of life. ${ }^{(16)}$

The descriptive analysis of the sociodemographic and clinical variables, as well as of the variables related to quality of life and asthma control, is presented in tables, where numerical variables are expressed as means and categorical variables are expressed as proportions.

Quantitative variables were tested for normality of distribution with the KolmogorovSmirnov test. For variables with normal distribution, we used the Student's t-test for the comparison of means between two groups, whereas, for those with non-normal distribution, we used the Mann-Whitney test. Pearson's coefficient was calculated to measure correlation between numerical variables. Multiple regression analysis was performed to identify the factors associated with the SGRQ scores. The SGRQ symptom score, impact score, activity score, and total score were used as dependent variables, whereas the ACT score, corrected for the covariates $\mathrm{FEV}_{1}$, duration of disease, and presence of GER, was used as an independent variable. Independent variables were selected on the basis of their clinical and statistical significance in the previous analyses. Two-tailed tests were used, and alpha probability level was set at 5\%. Statistical analysis was carried out with the Statistical Package for the Social Sciences, version 16.0 (SPSS Inc., Chicago, ll, USA).

\section{Results}

We evaluated 59 patients, most of whom were female, and the mean age was $55.0 \pm$ 12.4 years. More than half of the patients had a comorbidity, such as systemic arterial hypertension, diabetes, allergic rhinitis, or GER. The median ACT score was 20.7 (range, 6-25).
The mean total SGRQ score was $31.9 \pm 21.5$ points (Table 1).

The ACT score showed statistically significant negative correlations with all SGRQ scores: total $(r=-0.72 ; p<0.01)$; symptoms $(r=-0.78$; $\mathrm{p}<0.01)$; activity $(\mathrm{r}=-0.67 ; \mathrm{p}<0.01)$; and impact $(r=-0.68 ; p<0.01)$. This means that better asthma control translates to better quality of life. There was also a statistically significant inverse correlation between the SGRQ impact score and $\mathrm{FEV}_{1}$ in percentage of predicted $(\mathrm{r}=$ $-0.33 ; p=0.04$; Table 2).

There were no significant differences in the SGRQ scores when patients were assessed for gender, level of education, smoking status, presence of allergic rhinitis, presence of systemic arterial hypertension, and presence of diabetes. When patients were assessed for presence of GER, there was a statistically significant difference in the SGRQ total score $(p=0.01)$, the SGRQ symptom score $(p=0.01)$, and the SGRQ impact score ( $p=0.02$; Table 3$)$.

Multiple regression analysis was performed to identify the best independent variables for predicting the impact estimated by the

Table 1 - Clinical and sociodemographic characteristics of 59 outpatients with asthma under treatment at the Walter Cantídio University Hospital outpatient clinic, Fortaleza, Brazil.

\begin{tabular}{|c|c|}
\hline Characteristic & Results \\
\hline Age, years ${ }^{\mathrm{a}}$ & $55.1 \pm 12.4$ \\
\hline Female gender, \% & 76.3 \\
\hline Smoking, \% & 5.0 \\
\hline \multicolumn{2}{|l|}{ Level of education, $\%$} \\
\hline Illiterate & 8.5 \\
\hline Literate/9 years of schooling & 91.5 \\
\hline \multicolumn{2}{|l|}{ Comorbidities, $\%$} \\
\hline Hypertension and/or diabetes & 57.6 \\
\hline Allergic rhinitis & 76.6 \\
\hline Gastroesophageal reflux & 49.2 \\
\hline Duration of disease, years ${ }^{\mathrm{a}}$ & $23.2 \pm 18.2$ \\
\hline $\mathrm{FEV}_{1}, \%$ of predicted ${ }^{\mathrm{a}}$ & $67.3 \pm 16.0$ \\
\hline \multicolumn{2}{|l|}{ SGRQ score ${ }^{\mathrm{a}}$} \\
\hline Total & $31.9 \pm 20.2$ \\
\hline Symptoms & $33.1 \pm 20.6$ \\
\hline Activity & $45.4 \pm 24.3$ \\
\hline Impact & $27.3 \pm 20.1$ \\
\hline ACT score $^{b}$ & $20.7(6.0-25.0)$ \\
\hline
\end{tabular}

SGRQ: Saint George's Respiratory Questionnaire; and ACT: asthma control test. ${ }^{a}$ Values expressed as mean \pm SD.

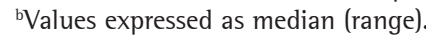


Table 2 - Correlation of quality of life, as measured by the Saint George's Respiratory Questionnaire, with the asthma control test score, $\mathrm{FEV}_{1}$, duration of disease, and patient age.

\begin{tabular}{|c|c|c|c|c|c|c|c|c|}
\hline \multirow{3}{*}{$\begin{array}{l}\text { SGRQ } \\
\text { score }\end{array}$} & \multicolumn{8}{|c|}{ Parameter } \\
\hline & \multicolumn{2}{|c|}{ ACT } & \multicolumn{2}{|c|}{$\mathrm{FEV}_{1}, \%$ of predicted } & \multicolumn{2}{|c|}{ Age, years } & \multicolumn{2}{|c|}{ Duration of disease, years } \\
\hline & $\mathrm{R}^{*}$ & $p$ & $\mathrm{R}^{*}$ & $p$ & $\mathrm{R}^{*}$ & $p$ & $\mathrm{R}^{*}$ & $p$ \\
\hline Total & -0.72 & $<0.01$ & 0.24 & 0.14 & -0.64 & 0.32 & -0.13 & 0.32 \\
\hline Symptoms & -0.78 & $<0.01$ & 0.24 & 0.16 & 0.13 & 0.34 & -0.058 & 0.68 \\
\hline Activity & -0.67 & $<0.01$ & 0.14 & 0.42 & -0.43 & 0.75 & 0.05 & 0.70 \\
\hline Impact & -0.68 & $<0.01$ & -0.33 & 0.04 & -0.19 & 0.14 & 0.13 & 0.30 \\
\hline
\end{tabular}

SGRQ: Saint George's Respiratory Questionnaire; and ACT: asthma control test. *Pearson's correlation.

SGRQ (dependent variable). The construction of the model took confounding variables and collinearity into account. The variables that explained the linear variation of the SGRQ total score and domain scores were identified through a backward stepwise process (Table 4). The variables identified as the best predictive variables for good quality of life (analyzing the SGRQ total score) were ACT score (coefficient = $-3.18 ; 95 \% \mathrm{Cl}:-4.14$ to -2.23 ) and duration of disease (coefficient $=-0.29 ; 95 \% \mathrm{Cl}:-0.54$ to -0.03$)$.

The model explained 59\% $\left(\mathrm{R}^{2}=0.59\right)$ of the impact on patient quality of life.

The ACT score was also found to be the best predictor of quality of life when the
SGRQ domain scores were analyzed-symptoms (coefficient $=-3.41 ; 95 \% \mathrm{Cl}:-4.45$ to -2.37 ); activity (coefficient $=-3.07 ; 95 \% \mathrm{Cl}:-4.57$ to -1.57 ); and impact (coefficient $=-2.68 ; 95 \%$ Cl: -3.71 to -1.65 ; Table 4). The negative coefficients indicate an inverse relationship of the ACT score with the SGRQ total score and the SGRQ domain scores, that is, better asthma control translates to better quality of life.

\section{Discussion}

The results of the present study show that asthma control as measured by the ACT correlated with quality of life as measured by the SGRQ and with all SGRQ domains (symptoms, activity, and impact).

Table 3 - Saint George's Respiratory Questionnaire total score and domain scores of the patients in the sample, stratified by patient characteristics.

\begin{tabular}{|c|c|c|c|c|c|c|c|c|}
\hline \multirow[t]{2}{*}{ Characteristic } & \multicolumn{8}{|c|}{ SGRQ total score and domain scores } \\
\hline & Total & $p^{*}$ & Symptoms & $p^{*}$ & Impact & $p^{*}$ & Activity & $p^{*}$ \\
\hline \multicolumn{9}{|l|}{ Gender } \\
\hline Female & $34.0 \pm 19.3$ & 0.21 & $36.0 \pm 20.6$ & 0.09 & $28.4 \pm 19.0$ & & $47.0 \pm 24.0$ & 0.26 \\
\hline Male & $25.4 \pm 22.4$ & & $25.0 \pm 19.5$ & & $26.3 \pm 23.0$ & 0.15 & $38.0 \pm 25.0$ & \\
\hline \multicolumn{9}{|l|}{ Level of education } \\
\hline Illiterate & $35.4 \pm 24.0$ & 0.20 & $27.0 \pm 20.0$ & 0.50 & $29.0 \pm 20.1$ & 0.81 & $64.0 \pm 21.5$ & 0.15 \\
\hline Literate & $31.6 \pm 20.1$ & & $33.8 \pm 20.0$ & & $27.0 \pm 20.0$ & & $43.0 \pm 24.0$ & \\
\hline \multicolumn{9}{|l|}{ Smoking } \\
\hline Yes & $50.0 \pm 11.7$ & 0.09 & $48.0 \pm 17.2$ & 0.23 & $47.9 \pm 16.0$ & 0.20 & $56.0 \pm 8.7$ & 0.12 \\
\hline No & $31.0 \pm 20.0$ & & $32.2 \pm 0.60$ & & $26.2 \pm 19.0$ & & $47.0 \pm 24.8$ & \\
\hline \multicolumn{9}{|l|}{ Allergic rhinitis } \\
\hline Yes & $31.1 \pm 20.3$ & 0.59 & $30.2 \pm 19.0$ & 0.10 & $26.0 \pm 20.1$ & 0.62 & $44.5 \pm 24.0$ & 0.65 \\
\hline No & $34.5 \pm 20.3$ & & $42.0 \pm 19.3$ & & $29.0 \pm 20.0$ & & $48.0 \pm 25.8$ & \\
\hline \multicolumn{9}{|l|}{ GER } \\
\hline Yes & $38.4 \pm 21.3$ & 0.01 & $39.5 \pm 23.0$ & 0.01 & $33.8 \pm 21.0$ & 0.02 & $48.6 \pm 27.0$ & 0.28 \\
\hline No & $25.3 \pm 17.2$ & & $26.5 \pm 14.0$ & & $21.4 \pm 16.0$ & & $41.7 \pm 20.0$ & \\
\hline \multicolumn{9}{|c|}{ Hypertension and/or diabetes } \\
\hline Yes & $29.3 \pm 17.9$ & 0.26 & $32.9 \pm 18.0$ & 0.92 & $23.4 \pm 19.0$ & 0.10 & $41.0 \pm 23.0$ & 0.12 \\
\hline No & $35.5 \pm 22.9$ & & $33.5 \pm 23.0$ & & $32.7 \pm 23.0$ & & $51.0 \pm 5.1$ & \\
\hline
\end{tabular}

SGRQ: Saint George's Respiratory Questionnaire; and GER: gastroesophageal reflux. *Unpaired Student's t-test. 
Table 4 - Multiple regression analysis of the Saint George's Respiratory Questionnaire total score and domain scores in relation to selected variables.

\begin{tabular}{|c|c|c|c|c|c|c|}
\hline Variable & Coefficient & $\mathrm{SE}$ & $\mathrm{t}$ & $p$ & $\begin{array}{c}95 \% \mathrm{Cl} \text { for the } \\
\text { coefficient }\end{array}$ & $\begin{array}{c}\text { Adjusted } \\
\mathrm{R}^{2}\end{array}$ \\
\hline \multicolumn{7}{|l|}{ SGRQ total score } \\
\hline Constant & 103.16 & 10.47 & 9.85 & $<0.001$ & $81.88-24.44$ & \\
\hline ACT score & -3.18 & 0.46 & -6.80 & $<0.001$ & -4.14 to -2.23 & \\
\hline Duration of disease & -0.29 & 0.12 & -2.33 & 0.026 & -0.54 to -0.03 & 0.59 \\
\hline \multicolumn{7}{|l|}{ SGRQ symptom score } \\
\hline Constant & 107.57 & 11.60 & 9.26 & $<0.001$ & 83.89-131.24 & \\
\hline ACT score & -3.41 & 0.51 & -6.69 & $<0.001$ & -4.45 to -2.37 & 0.59 \\
\hline \multicolumn{7}{|l|}{ SGRQ activity score } \\
\hline Constant & 110.80 & 15.14 & 7.316 & $<0.001$ & 79.91-141.69 & \\
\hline ACT score & -3.07 & 0.73 & -4.18 & $<0.001$ & -4.57 to -1.57 & 0.36 \\
\hline \multicolumn{7}{|l|}{ SGRQ impact score } \\
\hline Constant & 80.33 & 10.65 & 7.540 & $<0.001$ & 58.68-101.98 & \\
\hline ACT score & -2.68 & 0.50 & -5.27 & $<0.001$ & -3.71 to -1.65 & 0.45 \\
\hline
\end{tabular}

Several studies have demonstrated that asthma patients have an impaired quality of life. ${ }^{(8-12)}$ One of the factors that are thought to contribute to this impairment is the presence of GER. One group of authors ${ }^{(17)}$ recently reported that effective treatment of GER improved quality of life in the 44 patients studied. In the present study, we found that the patients with GER had poorer quality of life than did those without GER. This is an important fact because it draws the physician's attention to the diagnosis and treatment of comorbidities of asthma.

There was no statistically significant difference in the SGRQ scores when the patients were assessed for smoking status. The likely explanation is the low proportion of smokers in the sample-only 5\% of the patients smoked.

According to the Global Initiative for Asthma, ${ }^{(2)}$ the primary goal of asthma treatment is to achieve optimal disease control, with few or no daytime or nighttime symptoms, no limitation of physical activity, minimal need for rescue medications, normal or near normal pulmonary function, and no exacerbations.

To address deficiencies in asthma control management, there is a need for item assessment questionnaires that reflect the multidimensional nature of the disease and that are easily administered and interpreted. ${ }^{(18)}$

Several questionnaires have been developed to assess asthma control, including the $\mathrm{ACT},{ }^{(4)}$ the asthma control questionnaire, ${ }^{(19)}$ the asthma therapy assessment questionnaire, ${ }^{(20)}$ and the asthma control scoring system. ${ }^{(21)}$ The ACT can discriminate between controlled and uncontrolled asthma, which makes it a useful instrument for clinicians and researchers.

Some objective measures, such as pulmonary function and symptom diary cards, are frequently used for assessing the degree of asthma control. However, quality of life involves multidimensional (physical, emotional, and social) aspects and is therefore difficult to estimate by means of objective parameters. ${ }^{(21,22)}$ Some studies have reported a poor correlation between pulmonary function (an objective parameter) and quality of life. ${ }^{(8,10-12,22,23)}$ In the present study, there was a poor correlation between $\mathrm{FEV}_{1}$ and quality of life as assessed by the SGRQ. In contrast, a good correlation was found between the ACT score and quality of life. Studies in this area are scarce and controversial. Recently, one group of authors reported a good correlation between the ACT score and quality of life as measured by the asthma quality of life questionnaire. ${ }^{(13)}$

The good correlation found in the sample of the present study can be explained by the fact that the ACT and the SGRQ comprise multidimensional aspects of asthma, including symptoms, activities of daily living, and selfrating of asthma control, all of which are factors that affect patient quality of life. 
In the present study, we found that the patients with longer duration of disease had better quality of life. A likely explanation for that finding is the learning effect (the development of strategies for coping with the disease).

One of the limitations of this study is the fact that clinical criteria alone were used for assessment of GER. However, this is a valid criterion and has been used in other studies, ${ }^{(24,25)}$ in addition to the fact that this was not our main focus.

The present study also has the inherent limitations that are common to observational, cross-sectional studies. The cause-and-effect relationship is a problem in those studies, and it is therefore impossible to determine whether asthma control is a cause or consequence of improved quality of life.

The sample size and power of the present study were appropriate for demonstrating an association between the ACT score and quality of life. A previous study ${ }^{(13)}$ found a correlation between the ACT score and quality of life as measured by the asthma quality of life questionnaire (0.69). In the present study, we found a Pearson's correlation of 0.72 between asthma control (ACT score) and quality of life (SGRQ score). Multivariate regression analysis revealed a satisfactory coefficient with a narrow confidence interval.

This was a convenience sample, and generalization is therefore unwarranted. Sample validity depends on the assumption that, to answer the study question, the sample adequately represents the target population. In convenience samples, this is merely a matter of judgment.

The results obtained for the sample evaluated in the present study favor the use of the ACT as a tool for assessing asthma control and, by extension, quality of life in patients with moderate to severe asthma.

\section{References}

1. World Health Organization. Global Surveillance, Prevention and Control of Chronic Respiratory Diseases: A Comprehensive Approach. Geneva: World Health Organization; 2007.

2. Global Initiative for Asthma. Global Strategy for Asthma Management and Prevention. Bethesda: National Institutes of Health; 2009.

3. Bateman ED, Boushey HA, Bousquet J, Busse WW, Clark TJ, Pauwels RA, et al. Can guideline-defined asthma control be achieved? The Gaining Optimal
Asthma Control study. Am J Respir Crit Care Med. 2004;170(8):836-44.

4. Nathan RA, Sorkness CA, Kosinski M, Schatz M, Li JT, Marcus P, et al. Development of the asthma control test: a survey for assessing asthma control. J Allergy Clin Immunol. 2004;113(1):59-65.

5. Roxo JP, Ponte EV, Ramos DC, Pimentel L, D'Oliveira Júnior A, Cruz AA. Portuguese-language version of the Asthma Control Test. J Bras Pneumol. 2010;36(2):159-66.

6. Jones PW, Quirk FH, Baveystock CM, Littlejohns P. A selfcomplete measure of health status for chronic airflow limitation. The St. George's Respiratory Questionnaire. Am Rev Respir Dis. 1992;145(6):1321-7.

7. Camelier A, Rosa FW, Salim C, Nascimento OA, Cardoso F, Jardim JR. Using the Saint George's Respiratory Questionnaire to evaluate quality of life in patients with chronic obstructive pulmonary disease: validating a new version for use in Brazil. J Bras Pneumol. 2006;32(2):114-22.

8. Juniper EF, Guyatt GH, Epstein RS, Ferrie PJ, Jaeschke R, Hiller TK. Evaluation of impairment of health related quality of life in asthma: development of a questionnaire for use in clinical trials. Thorax. 1992;47(2):76-83.

9. Fernandes AL, Oliveira MA. Avaliação da qualidade de vida na asma. J Pneumol. 1997;23(3):148-52.

10. Adams R, Wakefield M, Wilson D, Parsons J, Campbell D, Smith B, et al. Quality of life in asthma: a comparison of community and hospital asthma patients. J Asthma. 2001;38(3):205-14.

11. Adams RJ, Wilson DH, Taylor A, Daly A, d'Espaignet E, Ruffin RE Psychological distress and quality of life among people with asthma in the Australian population. Respirology. 2003;8(4):67-81.

12. Juniper EF. Assessing asthma quality of life: its role in clinical practice. Breathe. 2005;1(3):192-205.

13. Kwon HS, Lee SH, Yang MS, Lee SM, Kim SH, Kim Dl, et al. Correlation between the Korean version of Asthma Control Test and health-related quality of life in adult asthmatics. J Korean Med Sci. 2008;23(4):621-7.

14. Vieira AA, Santoro IL, Dracoulakis S, Caetano LB, Fernandes AL. Anxiety and depression in asthma patients: impact on asthma control. J Bras Pneumol. 2011;37(1):13-8.

15. Pereira C. Espirometria. J Pneumol. 2002;28(Suppl 3):S1-S82

16. Ferrer M, Villasante C, Alonso J, Sobradillo V, Gabriel R, Vilagut G, et al. Interpretation of quality of life scores from the St George's Respiratory Questionnaire. Eur Respir J. 2002;19(3):405-13.

17. dos Santos LH, Ribeiro 10, Sánchez PG, Hetzel JL, Felicetti JC, Cardoso PF. Evaluation of pantoprazol treatment response of patients with asthma and gastroesophageal reflux: a randomized prospective double-blind placebo-controlled study. J Bras Pneumol. 2007;33(2):119-27.

18. Schatz M, Mosen D, Apter AJ, Zeiger RS, Vollmer WM, Stibolt TB, et al. Relationships among quality of life, severity, and control measures in asthma: an evaluation using factor analysis. J Allergy Clin Immunol. 2005;115(5):1049-55.

19. Juniper EF, O’Byrne PM, Guyatt GH, Ferrie PJ, King DR. Development and validation of a questionnaire to measure asthma control. Eur Respir J. 1999;14(4):902-7. 
20. Vollmer WM, Markson LE, O'Connor E, Sanocki LL, Fitterman L, Berger M, et al. Association of asthma control with health care utilization and quality of life. Am J Respir Crit Care Med. 1999;160(5 Pt 1):1647-52.

21. Boulet LP, Boulet V, Milot J. How should we quantify asthma control? A proposal. Chest. 2002;122(6):2217-23.

22. Carranza Rosenzweig JR, Edwards L, Lincourt W, Dorinsky P, ZuWallack RL. The relationship between health-related quality of life, lung function and daily symptoms in patients with persistent asthma. Respir Med. 2004;98(12):1157-65.

23. Juniper EF, Guyatt GH, Ferrie PJ, Griffith LE. Measuring quality of life in asthma. Am Rev Respir Dis. 1993;147(4):832-8.

24. Debley JS, Carter ER, Redding GJ. Prevalence and impact of gastroesophageal reflux in adolescents with asthma: a population-based study. Pediatr Pulmonol. 2006;41(5):475-81.

25. Field SK, Underwood M, Brant R, Cowie RL. Prevalence of gastroesophageal reflux symptoms in asthma. Chest. 1996;109(2):316-22.

\section{About the authors}

\section{Eanes Delgado Barros Pereira}

Associate Professor. Department of Clinical Medicine, Federal University of Fortaleza, Fortaleza, Brazil.

Antonio George de Matos Cavalcante

Pulmonologist. Federal University of Ceará Hospital das Clínicas, Fortaleza, Brazil.

Eduardo Nolla Silva Pereira

Medical Student. Federal University of Ceará School of Medicine, Fortaleza, Brazil.

Pedro Lucas

Medical Student. Federal University of Ceará School of Medicine, Fortaleza, Brazil.

\section{Marcelo Alcântara Holanda}

Adjunct Professor. Department of Clinical Medicine, Federal University of Fortaleza, Fortaleza, Brazil. 